\title{
Learning facts during aging: the benefits of curiosity
}

*Giulia Galli ${ }^{1}$, Miroslav Sirota ${ }^{2}$, Matthias J. Gruber ${ }^{3}$, Bianca Elena Ivanof ${ }^{1,4}$, Janani Ganesh $^{1}$, Maurizio Materassi ${ }^{1}$, Alistair Thorpe ${ }^{2}$, Vanessa Loaiza ${ }^{2}$, Marinella Cappelletti ${ }^{4}$, Fergus I. M. Craik ${ }^{5}$

${ }^{1}$ Department of Psychology, Kingston University, United Kingdom

${ }^{2}$ Department of Psychology, University of Essex, United Kingdom

${ }^{3}$ School of Psychology, Cardiff University, United Kingdom

${ }^{4}$ Department of Psychology, Goldsmiths University of London, United Kingdom

${ }^{5}$ Rotman Research Institute at Baycrest, Canada

\section{${ }^{*}$ Corresponding Author:}

Department of Psychology, Faculty of Arts and Social Sciences, Kingston University Penrhyn Road, Kingston Upon Thames, Surrey KT1 2EE United Kingdom g.galli@kingston.ac.uk

This is a version of manuscript accepted for publication in the journal Experimental Aging Research. This manuscript has not yet been published and may thus not reflect its final version. 


\section{ABSTRACT}

Background/Study Context: Recent studies have shown that young adults better remember factual information they are curious about. It is not entirely clear, however, whether this effect is retained during aging. Here, we investigated curiosity-driven memory benefits in young and elderly individuals.

Methods: In two experiments, young (age range 18-26) and older (age range 65-89) adults read trivia questions, and rated their curiosity to find out the answer. They also attended to task-irrelevant faces presented between the trivia question and the answer. We then administered a surprise memory test to assess recall accuracy for trivia answers, and recognition memory performance for the incidentally-learned faces.

Results: In both young and elderly adults, recall performance was higher for answers to questions that elicited high levels of curiosity. In Experiment 1 we also found that faces presented in temporal proximity to curiosity-eliciting trivia questions were better recognized, indicating that the beneficial effects of curiosity extended to the encoding of task-irrelevant material.

Conclusions: These findings show that elderly individuals benefit from the memoryenhancing effects of curiosity. This may lead to the implementation of learning strategies that target and stimulate curiosity in aging. 


\section{INTRODUCTION}

Over the centuries, philosophers, psychologists and educational scientists have speculated on the concept of curiosity. Curiosity has been described as an intrinsic motivation to explore the environment (Harlow, Harlow \& Meyer, 1950), a need to make sense of the world (Chen, Stotland \& Wolfe, 1955), and a motive to reduce negative states evoked by uncertainty, novelty, arousal or information gaps (Berlyne, 1954; Hebb, 1955; Loewenstein, 1994). Despite the lack of agreement on the definition and exact nature of curiosity (Kidd \& Hayden, 2015), its key role in education, scientific progress and other domains of human activity is widely recognized. For instance, research has demonstrated that curiosity is a strong predictor of academic achievement, even stronger than intelligence (von Stumm, Hell \& Chamorro-Premuzic, 2011), and that it is a key determinant in job performance and learning at work (Reio \& Wiswell, 2001).

Although the relationship between curiosity and intellectual abilities during childhood and early adulthood is well recognized, little empirical work has been conducted on curiosity in older adults. Evidence exists that elderly individuals are more curious than young adults (Mascherek and Zimprich, 2012), and that in the elderly curiosity levels drive individual differences in crystallized intelligence (von Stumm \& Deary, 2012). However, most studies focused on variables that, although in part conceptually overlapping, are only indirectly related to curiosity, such as need for cognition (the tendency for an individual to engage in effortful cognitive activities,

Cacioppo \& Petty, 1982) and openness to experience (a personality dimension of the Five Factor Model related to cognitive flexibility, need for variety and depth of emotional experience, McRae \& John, 1992). Longitudinal studies have shown that 
during aging scores on need for cognition scales predicted global cognitive status after a few years (Baer et al., 2013), and were positively correlated with problem solving abilities (Bye \& Pushkar, 2009). In addition, older adults with higher openness to experience scores performed better in a number of cognitive tasks including memory, visual and spatial abilities (Sharp, Reynolds, Pedersen \& Gatz, 2010), and had reduced age-related gray matter loss in brain regions associated with higher cognitive functioning (Taki et al., 2012). Taken together, these findings support anecdotal evidence on the benefits of a "hungry mind" in the elderly, and suggest that personality traits related to curiosity mitigate age-related changes in cognition and brain structure. However, the specific contribution of curiosity in cognitive aging is still largely unknown.

The relationship between curiosity and cognition may not only be reflected in a correlation between dispositional curiosity and cognitive abilities, but also in an effect of transient changes of curiosity levels on cognitive performance. This line of research has been explored recently in young adults by inducing curiosity with obscure trivia questions to which the answer is presumably not known (Kang et al., 2009; Gruber, Gelman \& Ranganath, 2014; Mullaney, Carpenter, Grotenhuis \& Burianec, 2014; McGillivray, Murayama \& Castel, 2015; Marvin \& Shohamy, 2016). Typically, a trivia question is presented, followed by a rating of curiosity to find out the answer, and then the answer. In a delayed memory test, participants are asked to recall the trivia answers, and their recall accuracy is analysed as a function of prior curiosity judgements. These studies have demonstrated that the more curious participants were about the trivia fact, the higher the likelihood that the answer would be later recalled (Kang et al., 2009; Gruber et al., 2014; Mullaney et al., 2014; 
McGillivray et al., 2015; Marvin \& Shohamy, 2016). Using the same experimental set up, Gruber et al. (2014) presented task-irrelevant faces between the trivia question and the answer, and assessed recognition memory accuracy for the faces in a surprise recognition memory test. The results showed that memory accuracy was higher for faces learned after a curiosity-inducing trivia question, that is, in a state of high curiosity. This evidence suggests that memory enhancements in young adults are not limited to the trivia fact itself, but extend to temporally-contiguous information (Gruber et al., 2014).

If dispositional curiosity and related personality traits in the elderly are associated with better cognitive functioning, one reasonable assumption is that, similar to young adults, elderly individuals would benefit from learning specific factual information in states of high curiosity. A recent investigation (McGillivray et al., 2015) showed that young and elderly adults had higher memory recall for trivia items they were very curious about, thus supporting the idea that the beneficial effect of curiosity on memory is preserved as individuals age. In the current study, we expanded upon this study and further investigated age-related patterns of curiosity effects on memory performance. We examined the effects of curiosity on the recall of trivia facts on a large sample of young and older adults and, building on the results of Gruber et al. (2014), we assessed whether curiosity affected the retrieval of information presented in temporal proximity to curiosity-eliciting trivia facts. To this aim, we presented task-irrelevant face stimuli immediately after curiosity-eliciting trivia questions, and tested recognition memory for those faces with a surprise oldnew recognition memory test in Experiment 1 and using the Remember/Know procedure (Tulving, 1985) in Experiment 2. Furthermore, we examined whether any 
relationship between curiosity and memory was modulated by baseline levels of curiosity measured by the Melbourne Curiosity Inventory (Naylor, 1981).

\section{EXPERIMENT 1}

\section{Methods}

\section{Participants}

We calculated that 60 participants, 30 per each age group, would enable us to detect a curiosity effect of medium size of $f=0.185-$ using a within-subject ANOVA, assuming $\alpha=0.05$ and $1-\beta=0.80-$ far below the effect size reported in other studies documenting the curiosity effect on recall of a similar design in young adults (e.g., $d=1.11 \approx f=0.49$, Kang et al,, 2009). We have adjusted upward the final sample size to adjust for possible attrition rate. Thus, data were collected from 70 participants. Data from 8 participants were collected but excluded prior to statistical analyses for the following reasons: low overall memory performance (proportion of false alarms $>$ proportion of hits; 2 young, 1 elderly), failure to comply with the task (one elderly participant only pressed the "old" response option in the recognition memory task), failure to complete the experiment ( 2 elderly) and scores above 10 on the Geriatric Depression Scale (GDS) indicating moderate depression (Yesavage et al., 1992; 2 young adults). Table 1 shows the demographic characteristics for the remaining 62 participants, who were 31 young (ages ranging from 19 to 23 years) and 31 older adults (ages ranging from 65 to 89 years). All participants were native English speakers, had normal or corrected-to-normal vision and a Mini Mental State Examination (MMSE; Folstein, Folstein \& McHugh, 1975) above 24, which is 
normally considered the cut-off for cognitive impairment (e.g., Fayers et al., 2005). Except for one elderly participant who reported mild use of benzodiazepines, no other participant reported current or recent use of psychotropic medication or sleeping aids. None of the participants reported a history of relevant psychiatric or neurological disease. Young participants were undergraduate students recruited at Kingston University, London. Elderly participants were recruited from local senior centres situated in London. Young participants received course credits or $£ 10$ for their participation. All elderly participants received $£ 10$. The experimental procedures were approved by the Kingston University Research Ethics Committee.

\section{Materials}

Stimuli were 104 trivia questions with corresponding answers, and 150 face stimuli from the CAL/PAL database (Minear \& Park, 2004). Trivia stimuli were selected from a larger pool of 216 trivia questions that had been evaluated in a pilot study. In this pilot study, 20 young adults were asked to rate their curiosity levels elicited by each trivia question, and the likelihood that they knew the answer, on a 6-point Likert scale. Since our interest was in trivia facts for which participants were not expected to have previous knowledge, we selected the 104 trivia stimuli with the lowest knowledge ratings $(M=2.84, S D=0.48)$. These 104 stimuli were used in the actual experiment (four were used for practice). The Appendix reports the list of trivia questions and answers used in the experiment, together with the mean curiosity rating elicited by each question in the pilot study and the actual experiment.

Face stimuli were greyscale, frontal view pictures of adults (75 males, 75 females) of different ages and ethnic groups. Individuals were shown with hair, neck and part of the shoulders. Half of the women had long hairstyles; all men had short 
hair, and half had moustaches and/or beards. Faces had no further distinctive features such as jewellery or glasses, and had neutral emotional expressions. Of the 150 face stimuli, 100 were used for incidental encoding in the study phase, 44 were used as new items in the test phase, and six were used for practice (four in the study phase, two as new items in the test phase). The order of stimuli and the assignment of faces to old-new status were randomized separately for each participant.

\section{Procedure}

Upon arrival to the laboratory, participants were given general information on the study and completed the MMSE. The MMSE was administered before the study phase to exclude from further testing participants with a MMSE score below the cutoff for normal cognitive functioning. Participants then sat in front of a computer screen and received instructions about the study task. Participants were not told that their memory for the study items would be tested in a subsequent test. Throughout all phases of the experiment, stimuli were presented in the centre of the computer screen on a grey background with the Cogent 2000 toolbox (http://www.vislab.ucl.ac.uk/cogent.php).

Figure 1 illustrates a sample study trial. Study trials began with a 1-second fixation point (a black plus sign on a grey background), followed by the presentation of the trivia question for 5 seconds, another fixation point for 3 seconds, and the presentation of the face for 3 seconds. Participants were instructed to judge whether the person depicted would know the answer to the trivia question, without pressing any button on the keypad. This task ensured that the participant paid attention to the face. The face was then replaced by a 3-second fixation, and by the curiosity rating slide which stayed on the screen for 3 seconds. As shown in Figure 1, the slide 
displayed the question "How curious are you about the answer?" and a numerical scale from 1 to 6 . Participants had to give their rating pressing one of six keys on the keyboard. They were instructed that ratings from 3 to 1 indicated progressively low curiosity judgements. These ratings were given with the three far left letter keys of the keyboard, with the farthest left key designating 1 ( I am not curious about the answer). Ratings from 4 to 6 indicated progressively high curiosity judgements. These ratings were given with the three far right letter keys of the keyboard, with the farthest right key designating 6 ( I am extremely curious about the answer). After another 2-second fixation, the trivia answer appeared for 2 seconds, and participants were then prompted to indicate whether they already knew the answer to the trivia question by pressing any of the three far left buttons for "no", and any of the three far right buttons for "yes". Trials given a "yes" response were excluded from further analysis of recognition memory and recall accuracy to avoid a confounding effect of previous knowledge on memory performance. A study trial ended with a fixation point that lasted for the whole duration of the inter-trial interval, which randomly varied between 3 and 4.5 seconds.

After the end of the study lists, participants were given a few minutes to rest and received the instructions for the surprise memory test for the faces. All 100 faces presented in the study phase were presented again along with 44 new ones. Each test trial started with a fixation point presented for 2 seconds, followed by the appearance of the face for 1 second. Participants had to indicate whether the face was presented before or not by pressing on the keyboard either the far left key with their left index finger, or the far right key with their right index finger. Response hand indicating "yes" or "no" was counterbalanced across participants. A fixation point was 
then presented for the whole duration of the inter-trial interval, which randomly varied between 4 and 5.5 seconds.

After the recognition memory test for faces, participants performed the recall test for the trivia answers. They were given a sheet with the list of all 100 trivia questions in random order, and were asked to write down as many answers they could recall from the study phase. Participants were further asked to fill out the GDS (Yesavage et al., 1992) and the state and trait scales of the Melbourne Curiosity Inventory (Naylor, 1981).

\section{Statistical analysis}

The main goal of the current study was to investigate whether curiosity benefits memory formation in older adults. To this end, recall of trivia answers and incidental memory for faces was assessed as a function of curiosity judgements during encoding. For both memory tests, three sets of analyses were carried out. In all three types of analysis, only trials for which participants indicated that they did not know the answer to the trivia question were included in the analyses. The mean number of these trials was $79.94(S D=10.24)$ in young and $84.29(S D=7.03)$ in older adults. First, we analysed the effects of curiosity, age and their interaction on the correct recognition and recall at the trial level. Such a procedure allows determining for each subject the probability that a given trial is remembered as a function of continuous curiosity levels. This analysis therefore included only old items and was performed across all curiosity judgements. We ran a series of generalised estimating equations (gee) using a binary logistic regression with an exchangeable correlation matrix. We used the gee because of the non-independence of the trials (trials were clustered within a participant). The reported means represent estimated marginal means and 
Cls represent Wald $95 \%$ confidence intervals. Second, to complement the trial level analysis and allow comparison with previous studies on young adults (Kang et al., 2009; Gruber et al., 2014; Mullanay et al., 2014) we analysed aggregated data. We ran a mixed model ANOVA with Group as between-subjects factor (young, elderly) and Curiosity as within-subjects factor (high, low). High curiosity judgements aggregated ratings 5 and 6 of the curiosity scale, and low curiosity judgements aggregated ratings 1 and 2 . In the aggregated data analysis, for the recall test memory accuracy was based on the percentage of correctly recalled answers. For the incidental memory task, memory accuracy was assessed with the discrimination index $\operatorname{Pr}$ (Snodgrass \& Corwin, 1988) that takes into account the performance for both old and new items. One young and one older participant were excluded from the aggregated data analysis because of a lack of low curiosity judgements. Third, to quantify the evidence to support the null or alternative hypothesis, we analysed the aggregated data using a Bayes factor analysis. In generic terms, a Bayes factor $(B F)$ is the ratio of the probability of the data given model $A$ (e.g., $H_{1}$ ) to the probability of the data given model $B\left(\right.$ e.g., $\left.\mathrm{H}_{0}\right)$. Thus, the Bayes factor expresses the ratio of marginal likelihood of the data under the model A (e.g., $\mathrm{H}_{1 \text { curiosity effect model) }}$


times the data are likely to occur under $\mathrm{H}_{1}$ compared with $\mathrm{H}_{0}$ or vice versa. For example, if $\mathrm{BF}_{10}$ value is 5 then the data are five times more likely to occur under the $H_{1}$. A Bayes Factor, $B F_{10}$ with a value lower than 1 indicates that the $H_{0}$ is more likely and with value greater than 1 indicates that $\mathrm{H}_{1}$ is more likely. Furthermore, the Bayes Factor values may also be interpreted as evidence categories, for example, values between 1 to 3 indicate anecdotal evidence to support the alternative hypothesis, whereas values greater than 100 indicates decisive evidence to support 
the alternative hypothesis (Jeffreys, 1961; Wetzels et al., 2011). Here, we calculated a JZS Bayes factor ANOVA with default prior scales using JASP (Love et al., 2015).

\section{Results}

Preliminary analyses: Differences between young and elderly in curiosity and overall memory performance

We first conducted a set of preliminary analyses to assess age-related differences in curiosity levels and overall memory abilities, that is, memory performance regardless of curiosity ratings. As can be seen in Table 1, curiosity levels were high in both groups. Young and elderly adults did not significantly differ in their Melbourne Curiosity Inventory State and Trait scores, $t(60)=1.21, p=.229, d=.31$, and $t(60)=$ $1.05, p=.298, d=.28$, respectively, and in mean curiosity ratings on the Likert scale during the study phase, $t(60)=0.62, p=.535, d=.16)$. The recall of trivia questions was higher in young compared to elderly adults, $t(60)=2.96, p=.004, d=.75$, but memory performance for incidentally learned faces was similar in the two groups, $t(60)=0.29, p=.769, d=.06$.

\section{Recall of answers to trivia questions eliciting high and low curiosity}

In a gee model, we found significant main effects of age $\left(\mathrm{M}_{\text {young }}=.64\right.$, Cl[.60, .69], $\left.M_{\text {elderly }}=.54, \mathrm{Cl}[.50, .59]\right)$, Wald $x^{2}(1)=8.81, p=.003$, and curiosity $\left(M_{1}=.56\right.$, $\mathrm{Cl}[.50, .61], M_{2}=.56, \mathrm{Cl}[.51, .62], M_{3}=.56, \mathrm{Cl}[.52, .61], M_{4}=.60, \mathrm{Cl}[.56, .64], M_{5}=$ $\left..62, \mathrm{Cl}[.58, .67], M_{6}=.65, \mathrm{Cl}[.61, .68]\right)$, Wald $\mathrm{X}^{2}(5)=19.03, p=.002$, on the percentage of correctly recalled items, Figure $2 \mathrm{~A}$. The interaction between curiosity and age was not significant, Wald $x^{2}(5)=6.13, p>.250$. These effects did not 
change when the model was adjusted for state and trait curiosity using the Melbourne Curiosity Inventory (Naylor, 1981) scores (main effect of age Wald $x^{2}(1)=$ $7.39, p=.007$; main effect of curiosity, Wald $X^{2}(5)=19.32, p=.002$; age $X$ curiosity interaction, Wald $\left.x^{2}(5)=6.01, p=.294\right)$. The analysis on the aggregated data collapsing low and high curiosity judgements converged with the trial-level analysis. The mixed-model ANOVA revealed a main effect of curiosity, $F(1,58)=10.73, p=$ $.002, \mathrm{n}_{\mathrm{p}}^{2}=.156$, indicating higher recall of trivia answers participants were curious about compared to trivia answers participants were less curious about, but no significant interaction with age, $F(1,58)=.04, p=.847, \eta_{p}^{2}=.001$, Table 2 .

A JZS Bayes factor ANOVA revealed that the model including the main effect of age $\left(\mathrm{BF}_{10}=7.4\right)$ and the model including the main effect of curiosity $\left(\mathrm{BF}_{10}=19.2\right)$ was preferred to the intercept-model only. More importantly, the main effects model was preferred to the interaction model by a Bayes factor of 3.6. Thus, this provides strong evidence against the hypothesis that curiosity interacts with age in recall.

\section{Recognition memory for faces learned under low and high curiosity states}

The gee model on the face recognition hit rate showed no main effect of age, ( $\mathrm{M}_{\text {young }}$ $\left.=.55, \mathrm{Cl}[.50, .59] \mathrm{M}_{\text {elderly }}=.58, \mathrm{Cl}[.53, .62]\right), \mathrm{X}^{2}(1)=0.76, p>.250$, but a significant enhancing effect of curiosity across all levels $\left(M_{1}=.53\right.$, Cl[.47, .59], $M_{2}=.54$, Cl[.49, $.58], M_{3}=.55, \mathrm{Cl}[.50, .59], M_{4}=.58, \mathrm{Cl}[.53, .62], M_{5}=.61, \mathrm{Cl}[.57, .65], M_{6}=.56$, $\mathrm{CI}[.52, .61]), \mathrm{X}^{2}(5)=13.53, p=.019$, Figure 2B. The interaction between age and curiosity was not significant, $\mathrm{X}^{2}(5)=3.25 p>.250$. These effects remained the same if the model was adjusted for state and trait curiosity (main effect of age, Wald $x^{2}(1)$ $=0.46, p>.250$; main effect of curiosity, Wald $x^{2}(5)=13.51, p=.019$; age $\mathrm{x}$ curiosity interaction, Wald $\left.x^{2}(5)=3.24, p>.250\right)$. The mixed-model ANOVA on the 
aggregated data confirmed the trial-level analysis revealing a main effect of curiosity, $F(1,58)=15.29, p=.001, \eta_{p}^{2}=.209$, but no interaction between age and curiosity $F(1,58)=0.93, p=.339, \eta_{p}^{2}=.016$, Table 3 .

A JZS Bayes factor ANOVA revealed that the model including the main effect of age $\left(\mathrm{BF}_{10}=0.4\right)$ was not preferred to the intercept-model only, whereas the model including the main effect of curiosity $\left(\mathrm{BF}_{10}=26.1\right)$ was preferred to the interceptmodel only. More importantly, the main effects model was preferred to the interaction model by a Bayes factor of 1.8. Thus, this provides anecdotal evidence against the hypothesis of age-related differences in curiosity-driven memory benefits.

\section{EXPERIMENT 2}

Experiment 2 was conducted for two reasons. First, we aimed to replicate the results of Experiment 1 on a different sample. Second, we aimed to examine the specific mechanisms underlying the enhanced incidental encoding for faces learned in states of high curiosity. Specifically, we assessed whether this effect would be driven by the retrieval of qualitative details of the study episode, that is, recollection, or by a general sense that the face has been encountered before, that is, familiarity (Mandler, 1980). For this reason, in the recognition memory test we implemented a Remember/Know judgement, which has traditionally been used to separate recollection from familiarity responses (Gardiner, 1988). We hypothesized that faces learned in states of high curiosity would attract a higher proportion of recollection responses. This hypothesis was based on the observation that the beneficial effects of curiosity on memory are supported by brain activations in the hippocampus (Gruber et al., 2014), a brain region involved in recollective processes (Eldridge, 
Knowlton, Furmanski, Bookheimer \& Engel, 2000). We further tested whether any contribution of recollection or familiarity differed between the two age groups. The study was preregistered at https://aspredicted.org/.

\section{Methods}

\section{Participants}

Participants were 40 young and 40 elderly adults (see Table 1 for demographics). Data from 3 participants were collected but excluded prior to statistical analyses from for the following reasons: low overall memory performance (proportion of false alarms > proportion of hits; 1 young adult), technical failure (1 elderly) and GDS score above 10 (1 young adult). All participants were native English speakers, had normal or corrected-to-normal vision and a MMSE score (Folstein et al., 1975) above 24. None of the participants reported a history of relevant psychiatric or neurological disease. Young participants were undergraduate students recruited at the University of Essex (UK). Elderly participants were recruited via newspaper advertisements and from local senior centres. Young participants received course credits or $£ 10$ for their participation. All elderly participants received $£ 10$. The experimental procedures were approved by the University of Essex Research Ethics Committee.

\section{Stimulus material, procedure and statistical analyses}

Stimulus materials, procedure and statistical analyses were identical to Experiment 1, except that in the recognition memory test subjects were asked to decide between three response alternatives. A 'Remember' response should be given if the face brought back specific details from its occurrence in the study phase (e.g., if the participant remembered the trivia question associated with that face, if the face 
occurred early or late during the task, or whether the face reminded he participant of something). A 'Know' response should be given if participants only had a general feeling that they had seen the face in the study phase. Finally, participants were asked to give a 'New' response if they thought that the face had not been presented before. Each response option was assigned to one of three response buttons of the keyboard. Participants used the middle and index finger of one hand for Remember and Know responses, respectively, and the middle finger of the other hand for New responses (response hand was counterbalanced across participants). The statistical analyses reflected this change and included a Response Type (Remember, Know) factor.

\section{Results}

Preliminary analyses: Differences between young and elderly in curiosity and overall memory performance

Elderly adults were more curious than younger adults during the experiment, as evidenced by higher scores at the Melbourne Curiosity Inventory - State, $t(78)=$ 2.66, $p=.009, d=0.59$, and higher curiosity ratings during the study phase (young adults: $M=3.53, S D=0.70$; elderly: $M=4.06, S D=0.58 ; t(78)=3.68, p<.001, d=$ $0.82)$. Young and elderly adults however did not differ in their dispositional curiosity levels indexed by the Melbourne Curiosity Inventory - Trait, $t(78)=1.98, p=.052, d$ $=0.44$, nor in their overall recall and recognition accuracy collapsed across Remember and Know responses ( $p s>.480)$. Remember judgements were equally likely in young and elderly adults (young adults: $M=0.15, S D=0.11$; elderly: $M=$ $0.18, S D=0.19 ; t(78)=1.00, p=.317, d=0.19$ ), as were Know judgements (young 
adults: $M=0.36, S D=0.10$; elderly: $M=0.42, S D=0.17 ; t(78)=1.89, p=.062, d=$ 0.43)

\section{Recall of answers to trivia questions eliciting high and low curiosity}

In the trial-level analysis, we found a non-significant main effect of age $\left(M_{y o u n g}=.58\right.$, $\left.\mathrm{CI}[.54, .62], M_{\text {elderly }}=.55, \mathrm{CI}[.51, .59]\right)$, Wald $\mathrm{X}^{2}(1)=1.20, p=.273$, and a significant main effect of curiosity $\left(M_{1}=.53, \mathrm{Cl}[.48, .57], M_{2}=.52, \mathrm{Cl}[.48, .56], M_{3}=.55, \mathrm{CI}[.52\right.$, $\left..59], M_{4}=.56, \mathrm{CI}[.52, .59], M_{5}=.62, \mathrm{CI}[.58, .65], M_{6}=.63, \mathrm{Cl}[.58, .67]\right)$, Wald $\mathrm{X}^{2}(5)=$

$34.71, p<.001$, on the percentage of correctly recalled items. The interaction between curiosity and age was not significant, Wald $X^{2}(5)=10.17, p=.071$. In the mixed-model ANOVA on the aggregated data, we found a main effect of curiosity $F(1,78)=20.51, p<.001, \eta_{p}^{2}=.208$, indicating higher recall of trivia answers participants were curious about compared to trivia answers participants were less curious about, but no significant interaction with age, $F(1,78)=.33, p=.567, \eta_{p}^{2}=$ .004, Table 3. A JZS Bayes factor ANOVA revealed anecdotal evidence that the intercept model was preferred to the model including the main effect of age $\left(\mathrm{BF}_{10}=\right.$ 7.4). Extreme evidence supported the model including the main effect of curiosity $\left(\mathrm{BF}_{10}=987.0\right)$. More importantly, the main effects model was preferred to the interaction model by a Bayes factor of 3.8. Thus, this provides moderate evidence against the hypothesis that curiosity interacts with age in recall.

\section{Recognition memory for faces learned under low and high curiosity states}

In the trial-level analysis, we found a non-significant main effect of age $\left(M_{\text {young }}=.27\right.$, CI[.23, .32], $\left.M_{\text {elderly }}=.28, \mathrm{CI}[.20, .36]\right)$, Wald $\mathrm{X}^{2}(1)<0.01, p=.947$, and a nonsignificant main effect of curiosity $\left(M_{1}=.29, \mathrm{Cl}[.23, .35], M_{2}=.27, \mathrm{CI}[.22, .32], M_{3}=\right.$ $\left..28, \mathrm{Cl}[.23, .33], M_{4}=.27, \mathrm{Cl}[.22, .33], M_{5}=.27, \mathrm{CI}[.22, .32], M_{6}=.27, \mathrm{CI}[.22, .34]\right)$, 
Wald $\mathrm{x}^{2}(5)=0.85, p=.974$, on Remember and Know responses. The interaction between curiosity and age was not significant, Wald $x^{2}(5)=7.35, p=.196$. The mixed-model ANOVA on the aggregated data revealed a main effect of response type, $F(1,78)=5.28, p=.024, \eta_{p}^{2}=.063$, indicating that Know responses were more accurate than Remember responses in both groups. In contrast with the results of Experiment 1, we found no main effect of curiosity, $F(1,78)=.01, p=.913, \eta_{p}^{2}=$ .000 . No interaction involving age, response type or curiosity emerged ( $p s>.088$ ). The JZS Bayes factor ANOVA revealed moderate evidence for the intercept model to be preferred to the model including the main effect of age $\left(\mathrm{BF}_{01}=3.6\right)$ and to the model including the main effect of curiosity $\left(\mathrm{BF}_{01}=5.9\right)$. The intercept model was strongly preferred to the interaction model $\left(\mathrm{BF}_{01}=76.1\right)$, and the main effects model was preferred to the interaction model by a Bayes factor of 3.7. Thus, this provides moderate evidence against the hypothesis that curiosity interacts with age in recognition.

\section{DISCUSSION}

In the current investigation, we showed that the way young and elderly individuals learn and recall factual information is a function of their levels of curiosity for that information. In Experiment 1 we also showed that curiosity for a trivia fact affected the retrieval of information presented in temporal proximity to those facts, indicating that the beneficial effects of curiosity extended to the encoding of task-irrelevant material.

Considering first the younger participants, our findings replicate on a large sample the results of previous studies that showed an enhancing effect of curiosity on the recall of trivia facts (Kang et al., 2009; Gruber et al., 2014; Mullaney et al., 
2014; Marvin \& Shohamy, 2016). One possible explanation for the observed curiosity-driven memory benefit is that curiosity exerts its effects on memory through reward-related mechanisms. According to an influential framework (Lowenstein, 1994), curiosity is an intrinsic drive to solve the gap between what one knows and what one wants to know. Given the enhancing effects of motivation and reward on memory formation (e.g., Adcock, Thangavel, Whitfield-Gabrieli, Knutson \& Gabrieli, 2006), it is plausible to assume that the intrinsic motivation to know the answer to a curiosity-inducing trivia question enhanced the formation of a memory trace for that answer. This link between curiosity and reward-motivated learning has received support recently from behavioural (Marvin \& Shohamy, 2016), and neuroimaging studies (Kang et al., 2009; Gruber et al., 2014). These studies demonstrated that the enhanced recall for curiosity-eliciting trivia facts was associated with brain activity in the mesolimbic dopaminergic circuit, which is implicated in reward-motivated learning (Miendlarzewska, Bavalier \& Schwartz, 2016). In the current work, we showed equal curiosity-driven memory benefits in young and older participants in the recall of trivia questions. This finding is in line with the results of McGillivray et al. (2015), who using a similar experimental set-up showed no age-related changes in curiosity-driven benefits in the recall of trivia facts. The lack of age-related differences may indicate that curiosity enhances memory in older individuals via the same reward-motivated learning as shown in younger adults. Alternatively, the curiosity-driven memory benefits observed in the elderly may be dependent upon different memory mechanisms. For instance, curiosity may have enhanced the formation of an episodic memory trace of the trivia information in younger adults, and the integration of the trivia information into a sematic network in the elderly. Either way, our findings show that curiosity benefits learning in the elderly as much as in 
younger adults. One relevant point to consider is that in both groups the beneficial effects of curiosity on memory recall were not affected by baseline curiosity levels, as measured by the Melbourne Curiosity Inventory. This suggests that the relationship between curiosity for specific facts and memory for those facts is not dependent upon how curious individuals are in general, at least in the context of the present work.

Whereas the enhancing effects of curiosity on the recall of trivia facts were strong in both experiments, curiosity-driven benefits on the incidental encoding of faces were less clear. In Experiment 1 we found an effect of curiosity in both groups, albeit weaker in the elderly, but in Experiment 2 neither group displayed curiositydriven memory benefits. The reason why this effect occurred in some participants, but not others, is currently unclear. Differences between the two experiments in terms of demographics, overall curiosity levels and memory performance (Table 1) do not appear large enough to explain the lack of curiosity effects in Experiment 2. It is more likely that the variability of the curiosity effect is dependent upon individual differences that are not captured in the context of the current study, such as the level of engagement with the task or the level of attention allocated to the processing of the faces during encoding. Of note, recognition memory performance in Experiment 2 was mainly supported by familiarity. If curiosity-driven memory benefits are largely driven by recollection as we hypothesized, one could assume that the lack of such effects may be due to a weak engagement of recollective processes, perhaps in combination with low engagement with the face processing task. Another possibility is that individual differences in curiosity-driven benefits reflect differences in the recruitment of dopaminergic circuits, as shown in Gruber et al. (2014). 
It should be noted that although we provide evidence for the beneficial effects of curiosity on memory, other factors might have played a key role in enhancing memory performance. For instance, memory benefits could result from an increase in attention or arousal associated with curiosity-eliciting facts, rather than from an increase in curiosity per se, or they could result from an increase in tip-of-the-tongue experiences associated with curiosity-eliciting trivia questions (Metcalfe, Schwartz \& Bloom, 2017). In addition, memory benefits could be influenced by variables that are conceptually overlapping with curiosity, such as need for cognition or interest. Future studies could improve upon the current design in different ways. First, by including measurements of attention and arousal, such as eye-tracking or skin conductivity, and of tip-of-the-tongue experiences. Second, by directly manipulating curiosity and similar constructs within the same experimental design and examining their relative contribution to memory formation.

Altogether, our findings show that age alone does not reduce the benefits of curiosity on memory. A variety of pedagogical approaches to teaching and learning, such as Problem Based or Case Based Learning, deliberately arouse curiosity, and similar interventions could be implemented to target and stimulate curiosity while learning in the elderly. Such interventions may result in changes in dispositional curiosity which, in turn, may affect memory and other cognitive abilities. 


\section{REFERENCES}

Adcock, A., Thangavel, A., Whitfield-Gabrieli, S., Knutson, B., \& Gabrieli, J. D. E. (2006). Reward-motivated learning: Mesolimbic activation precedes memory formation. Neuron, 50, 507-517.

Baer, L.H., Tabri, N., Blair, M., Bye, D., Li, K.Z., \& Pushkar, D. (2013). Longitudinal associations of need for cognition, cognitive activity, and depressive symptomatology with cognitive function in recent retirees. The Journals of Gerontology. Series B, Psychological Sciences and Social Sciences, 68, 655664.Berlyne, D.E. (1954). An experimental study of human curiosity. British Journal of Psychology, 45, 256-265.

Bye, D., \& Pushkar, D. (2009). How need for cognition and perceived control are differentially linked to emotional outcomes in the transition to retirement. Motivation and Emotion, 33, 320-332.

Cacioppo, J. T., \& Petty, R. E. (1982). The need for cognition. Journal of Personality and Social Psychology, 42, 116-131.

Chen, A.R., Stotland, E., \& Wolfe, D.M. (1955). An experimental investigation of need for cognition. Journal of Abnormal Psychology, 51, 291-294.

Eldridge, L.L., Knowlton, B.J., Furmanski, C.S., Bookheimer, S.Y., \& Engel, S.A. (2000). Remembering episodes: A selective role of the hippocampus during retrieval. Nature Neuroscience, 3, 1149-1152.

Fayers, P.M., Hjermstad, M.J., Ranhoff, A.H., Kaasa, S., Skogstad, L., Klepstad, P., \& Loge, J.H . (2005). Which mini-mental state exam items can be used to 
screen for delirium and cognitive impairment? Journal of Pain and Symptom Management, 30, 41-50.

Folstein, M.F., Folstein, S.E., \& McHugh, P.R. (1975). "Mini-mental state". A practical method for grading the cognitive state of patients for the clinician. Journal of Psychiatric Research, 12, 189-198.

Goff, M., \& Ackerman, P. L. (1992). Personality-intelligence relations: Assessment of typical intellectual engagement. Journal of Educational Psychology, 84, 537553.

Gorbach, T., Pudas, S., Lundquist, A., Oradd, G., Josefsson, M., Salami, A., de Luna, X., \& Nyberg L. (2016). Longitudinal association between hippocampus atrophy and episodic decline. Neurobiology of Aging, 51, 167-176.

Gruber, M.J., Gelman, B.D., \& Ranganath, C. (2014). States of Curiosity Modulate Hippocampus-Dependent Learning via the Dopaminergic Circuit. Neuron, 84, 486-496.

Harlow, H.F., Harlow, M.K., \& Meyer, D.R. (1950). Learning motivated by a manipulation drive. Journal of Experimental Psychology, 40, 228-234.

Hebb, D.O. (1955). Drives and the C.N.S. (conceptual nervous system). Psychological Reviews, 62, 243-254.

Jeffreys, H. (1961). The Theory of Probability (3 ed.). Oxford, UK: Oxford University Press.

Kang, M.J., Hsu, M., Krajbich, I.M., Loewenstein, G., McClure, S.M., Wang, J.T., \& Camerer, C.F. (2009). The wick in the candle of learning: epistemic curiosity activates reward circuitry and enhances memory. Psychological Science, 20, 963-973. 
Kidd, C, \& Hayden, B.Y. (2015). The psychology and neuroscience of curiosity. Neuron, 88, 449-460.

Litman, J.A. (2005). Curiosity and the pleasures of learning: wanting and liking new information. Cognition and Emotion, 19, 793-814.

Loewenstein, G. (1994). The psychology of curiosity; a review and reinterpretation. Psychological Bullettin, 116, 75-98.

Love, J., Selker, R., Marsman, M., Jamil, T., Dropmann, D., Verhagen, A. J., Ly, A., Gronau, Q. F., Smira, M., Epskamp, S., Matzke, D., Wild, A., Rouder, J. N., Morey, R. D. \& Wagenmakers, E.-J. (2015). JASP (Version 0.7)[Computer software].

McGillivray, S., Murayama, K., \& Castel, A.D. (2015). Thirst for knowledge: The effects of curiosity and interest on memory in younger and older adults. Psychology and Aging, 30, 835-841.

McRae, R.R., \& John, O.P. (1992). An introduction to the Five-Factor Model and its applications Journal of Personality, 60, 175-215.

Mandler, G. (1980). Recognizing: The judgement of previous occurrence. Psychological Reviews, 87, 252-271.

Mascherek, A., \& Zimprich, D. (2012). Age-related differences in typical intellectual engagement in young and old adults. Experimental Aging Research, 38, 6386.

Marvin, C.B., \& Shohamy, D. (2016). Curiosity and reward: Valence predicts choice and information prediction errors enhance learning. Journal of Experimental Psychology: General, 145, 266-272. 
Metcalfe, J., Schwartz, B.L., \& Bloom, P.A. (2017). The tip-of-the-tongue state and curiosity. Cognitive Research: Principles and Implications, 2, 31.

Miendlarzewska, E.A., Bavalier, D., \& Schwartz, S. (2016). Influence of reward motivation on human declarative memory. Neuroscience and Behavioral Reviews, 61, 156-176.

Minear, M. \& Park, D.C. (2004). A lifespan database of adult facial stimuli. Behavior Research Methods, Instruments, \& Computers. 36, 630-633.

Naylor, F. D. (1981). A state-trait curiosity inventory. Australian Psychologist, 16, 172-183.

Mullaney, K.M., Carpenter, S.K., Grotenhuis, C., \& Burianek, S. (2014). Waiting for feedback helps if you want to know the answer: the role of curiosity in the delay of feedback benefit. Memory and Cognition, 42, 1273-1284.

Reio, T.G.. \& Wiswell, A. (2000). Field investigation of the relationship among adult curiosity, workplace learning, and job performance. Human Resource Development Quarterly, 11, 5-30.

Sharp, E.S., Reynolds, C.A., Pedersen, N.L., \& Gatz, M. (2011). Cognitive engagement and cognitive aging: is openness protective? Psychology and Aging, 25, 60-73.

Snodgrass, J.G., \& Corwin, J. (1988). Pragmatics of measuring recognition memory: applications to dementia and amnesia. Journal of Experimental Psychology: General, 117, 34-50.

Taki, Y., Thyreau, B., Kinomura, S., Sato, K., Goto, R., Wu, K., Kawashima, R. \& Fukuda, H. (2012). A longitudinal study of the relationship between 
personality traits and the annual rate of volume changes in regional gray matter in healthy adults. Human Brain Mapping, 34, 3347-3353.

Tulving, E. (1985). Memory and consciousness. Canadian Psychology, 26, 1-12.

von Stumm, S., \& Deary, I.J. (2012). Typical intellectual engagement and cognition in the ninth decade of life: The Lothian Birth Cohort 1921. Psychology and Aging, 27, 761-767.

Von Stumm, S., Hell, B., \& Chamorro-Premuzic, T. (2011). The hungry mind: intellectual curiosity is the third pillar of academic performance. Perspectives on Psychological Science, 6, 574-588.

Wetzels, R., Matzke, D., Lee, M.D., Rouder, J.N., Iverson, F.J., \& Wagenmakers, E.J. (2011). Statistical evidence in experimental psychology. Perspectives on Psychological Science, 6, 291-298.

Yesavage, J.A., Brink, T.L., Rose, T.L., Lum, O., Huang, V., Adey, M., \& Leirer, V.O. (1982). Development and validation of a geriatric depression screening scale: a preliminary report. Journal of Psychiatry Research, 17, 37-49.

Yonelinas, A.P. (2002). The nature of recollection and familiarity: a review of 30 years of research. Journal of Memory and Language, 46, 441-517. 


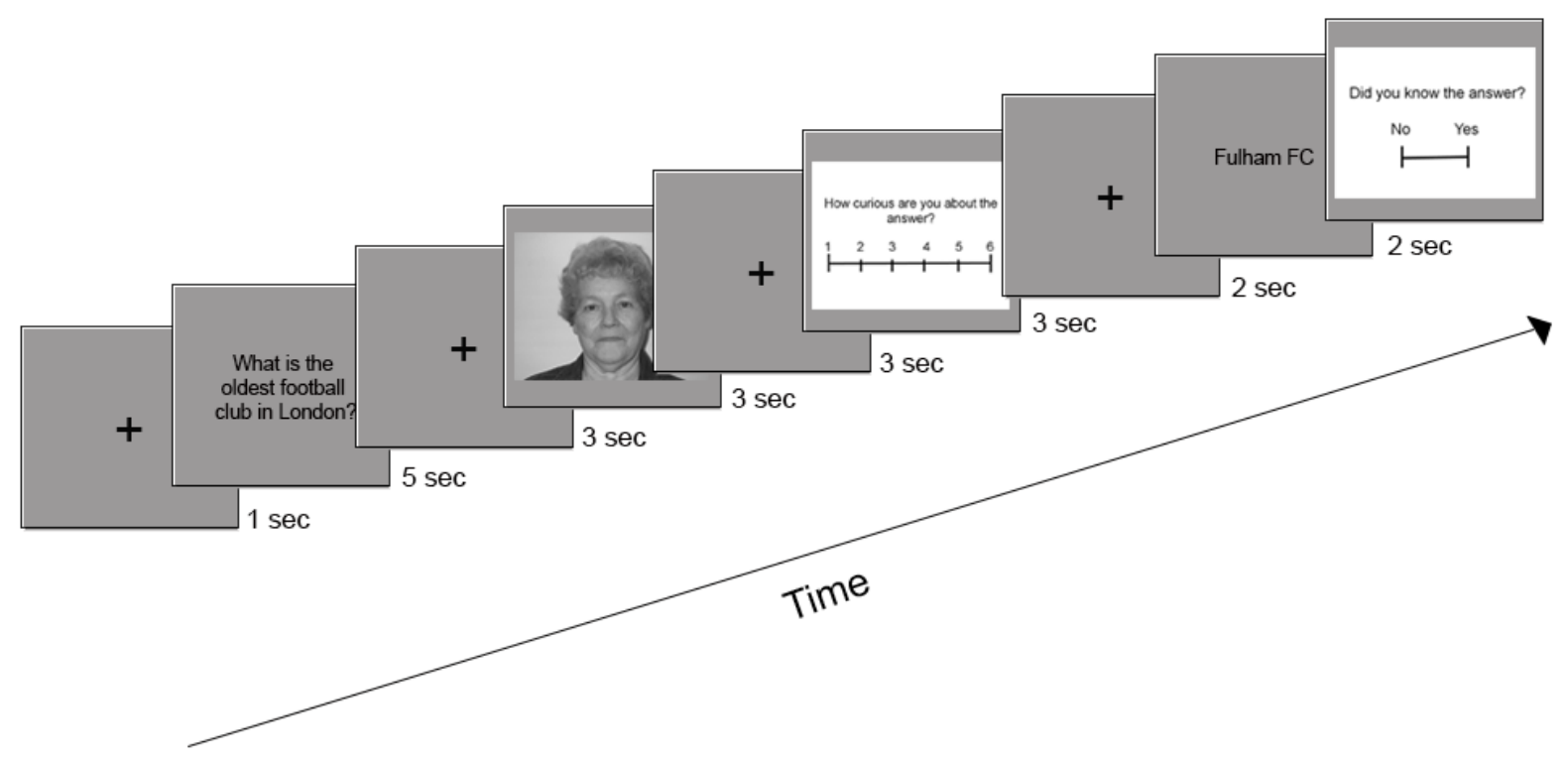

Figure 1: Schematic illustration of the experimental procedure. Participants were first presented with a trivia question. Then, a face stimulus appeared and participants decided whether the person depicted would know the answer to the trivia question or not. Next, participants rated their curiosity to find out the answer on Likert scale from 1 to 6 using the keypad, and at the end of the trial they indicated whether they knew the answer to the trivia question. 

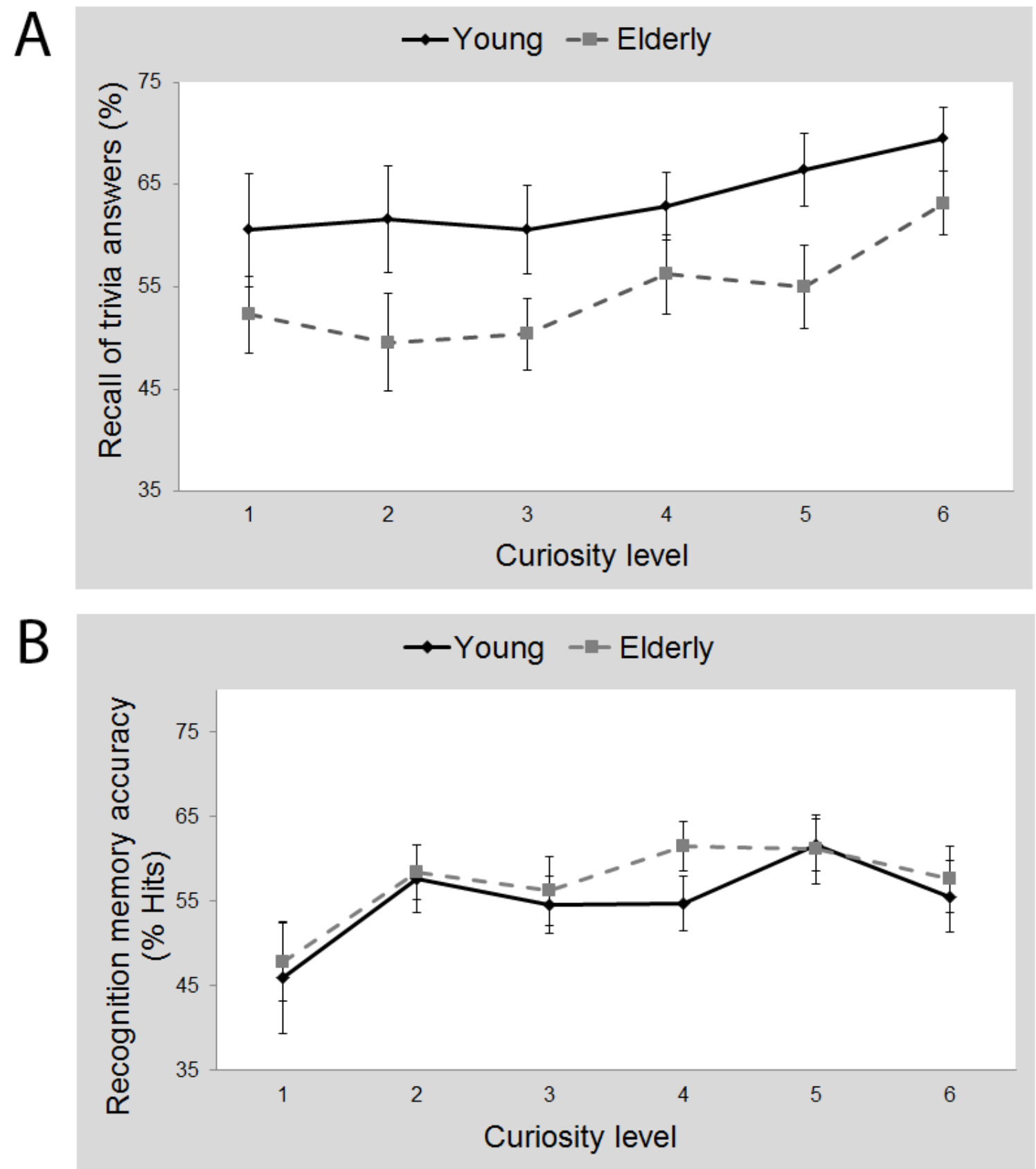

Figure 2: Memory performance as a function of prior curiosity judgement in the recall of trivia answers $(\mathrm{A})$ and in the recognition memory test for incidentally encoded faces (B). Bars depict the standard error. 
n

Experiment 1

Experiment 2

\section{Demographics}

Age (years)

Experiment 1

Experiment 2

Education (years)

Experiment 1

Experiment 2

Gender (F/M)

Experiment 1

Experiment 2

\section{Cognitive scores}

MMSE

Experiment 1

Experiment 2

Overall recognition $(\mathrm{Pr})$

Experiment 1

Experiment 2

Overall recall (\%)

Experiment 1

Experiment 2

\section{Questionnaires}

GDS

Experiment 1

Experiment 2

MCl-State

Experiment 1

Experiment 2
31

31

40
$20.1(1.2)$

$19.6(1.7)$

$13.8(0.5)$

$13.2(0.6)$

$21 / 10$

$27 / 13$
$74.1(6.5)$

$69.1(4.0)$

$14.1(2.9)$

$14.4(2.1)$

19/12

$28 / 12$
$29.3(0.9)$

28.6 (1.4)

$28.9(1.2)$

28.6 (1.2)

$0.32(0.2)$

$0.28(0.11)$

$0.31(0.1)$

$0.30(0.16)$

63.4 (12.9)

$57.2(13.5)$

53.5 (13.6)

55.9 (13.6)
$3.0(2.4)$

$4.1(2.7)$

58.4 (11.0)

$57.3(9.2)$
$2.3(2.7)$

$1.4(1.8)$

$61.7(10.8)$

$62.6(8.8)$

MCl-Trait 
Experiment 1

Experiment 2
$62.0(11.0)$

$60.8(6.8)$
$65.1(12.0)$

$64.2(8.6)$

Table 1: Characteristics of the sample in the two experiments. MMSE = Mini Mental State Examination (Folstein et al., 1975); GDS = Geriatric Depression Scale (Yesavage et al., 1992); $\mathrm{MCl}=$ Melbourne Curiosity Inventory (Naylor, 1981). $\mathrm{Pr}=$ discrimination index (Snodgrass \& Corwin, 1988). Standard deviations are displayed in parentheses. 
Table 2: Recall accuracy. Percentage of recall for trivia answers that elicited very high (ratings 5-6) and very low (ratings 1-2) curiosity in young and older adults. Standard deviations are displayed in parentheses. 
$\%$ High curiosity hits

60.79 (15.63)

59.87 (18.20)

$\%$ Low curiosity hits

$48.50(20.22)$

53.68 (18.75)

$\%$ False alarms

24.89 (10.98)

$27.52(13.81)$

High curiosity $\mathrm{Pr}$

$0.36(0.19)$

$0.33(0.18)$

Low curiosity $\mathrm{Pr}$

$0.24(0.24)$

$0.26(0.17)$

Table 3: Recognition memory accuracy. Recognition accuracy for faces learned in a state of very high (ratings 5-6) and very low (ratings 1-2) curiosity in young and older adults. $\mathrm{Pr}=$ discrimination index (Snodgrass and Corwin, 1988). Standard deviations are displayed in parentheses. 
$\%$ High curiosity recalled

$65.22(15.51)$

$60.67(19.61)$

\% Low curiosity recalled

56.48 (15.99)

49.39 (20.16)

High curiosity $\mathrm{Pr}-\mathrm{R}$

$0.12(0.10)$

$0.11(0.15)$

Low curiosity $\mathrm{Pr}-\mathrm{R}$

$0.11(0.09)$

$0.14(0.21)$

High curiosity $\mathrm{Pr}-\mathrm{K}$

$0.17(0.13)$

$0.20(0.14)$

Low curiosity $\mathrm{Pr}-\mathrm{K}$

$0.19(0.14)$

$0.16(0.22)$

Table 4: Recall and recognition memory accuracy in Experiment 2. The percentage of recall is calculated over the total number of very high and very low curiosity ratings (ratings 5-6 and 1-2, respectively). $\operatorname{Pr}=$ discrimination index (Snodgrass and Corwin, 1988) for Remember $(\mathrm{Pr}-\mathrm{R})$ and Know $(\mathrm{Pr}-\mathrm{K})$ responses. Standard deviations are displayed in parentheses. 


\section{Appendix}

List of trivia items used in Experiments 1 and 2, mean curiosity rating collapsed across the two experiments and mean curiosity ratings in the pilot study. Standard deviations are displayed in parentheses.

\begin{tabular}{|c|c|c|c|c|}
\hline Trivia question & Trivia answer & Mean curi & ity rating & \\
\hline & & $\begin{array}{l}\text { Young } \\
\text { adults }\end{array}$ & Elderly & Pilot study \\
\hline $\begin{array}{l}\text { In what year did England win the Rugby world } \\
\text { cup? }\end{array}$ & 2003 & $2.37(1.34)$ & $2.76(1.60)$ & $3.10(1.52)$ \\
\hline $\begin{array}{l}\text { Who was the first Twitter user to reach } 20 \text { million } \\
\text { followers? }\end{array}$ & Lady Gaga & $3.44(1.59)$ & $2.43(1.58)$ & $2.30(1.26)$ \\
\hline $\begin{array}{l}\text { On average how many babies have been born } \\
\text { from people who met on Match.com? }\end{array}$ & One million & $3.90(1.61)$ & $2.45(1.63)$ & $2.60(1.31)$ \\
\hline What football club is the oldest in London? & Fulham & $2.82(1.63)$ & $3.25(1.65)$ & $3.05(1.70)$ \\
\hline $\begin{array}{l}\text { How many hamburgers does McDonald's sell } \\
\text { every second of every day? }\end{array}$ & 75 & $3.52(1.69)$ & $2.67(1.66)$ & $2.65(1.14)$ \\
\hline What is making Hugh Hefner go deaf? & Viagra & $3.22(1.71)$ & $2.96(1.61)$ & $3.45(2.01)$ \\
\hline How many Facebook users are there? & 1.15 billion & $3.30(1.71)$ & $2.99(1.62)$ & $2.45(1.50)$ \\
\hline $\begin{array}{l}\text { How many hours worth of videos are uploaded on } \\
\text { YouTube every minute? }\end{array}$ & 100 hours & $3.71(1.55)$ & $2.64(1.64)$ & $3.25(1.59)$ \\
\hline $\begin{array}{l}\text { On average how long does a person wait at the } \\
\text { traffic lights in their lifetime? }\end{array}$ & 2 weeks & $3.25(1.56)$ & $3.14(1.72)$ & $2.85(1.39)$ \\
\hline $\begin{array}{l}\text { On average how many pairs of underwear do men } \\
\text { buy in a year? }\end{array}$ & 3.4 & $3.54(1.45)$ & $2.70(1.53)$ & $3.15(1.76)$ \\
\hline In what city was chewing gum invented? & New York & $3.23(1.22)$ & $2.78(1.56)$ & $3.20(1.40)$ \\
\hline $\begin{array}{l}\text { The Empire State Building is composed of how } \\
\text { many bricks? }\end{array}$ & 10 million & $3.19(1.58)$ & $3.41(1.76)$ & $3.20(1.54)$ \\
\hline $\begin{array}{l}\text { How many rooms does the Buckingham palace } \\
\text { have? }\end{array}$ & 775 & $3.29(1.53)$ & $3.07(1.49)$ & $3.20(1.54)$ \\
\hline $\begin{array}{l}\text { How much time does a person spend in the toilet } \\
\text { in their lifetime? }\end{array}$ & 3 years & $3.75(1.51)$ & $2.97(1.78)$ & $3.45(1.61)$ \\
\hline What sport was first filmed in $1894 ?$ & Boxing & $2.80(2.09)$ & $3.88(1.58)$ & $2.65(1.31)$ \\
\hline How old was the world's youngest pope? & 11 years old & $3.03(1.59)$ & $3.71(1.60)$ & $2.75(1.80)$ \\
\hline What was the game bingo originally called? & Beano & $3.22(1.47)$ & $3.39(1.66)$ & $3.65(1.93)$ \\
\hline $\begin{array}{l}\text { How many calories do you burn from chewing } \\
\text { gum for an hour? }\end{array}$ & 20 & $3.92(1.59)$ & $3.15(1.80)$ & $3.10(1.68)$ \\
\hline What's the world's fastest car? & $\begin{array}{l}\text { Hennessey } \\
\text { Venom }\end{array}$ & $3.31(1.65)$ & $3.49(1.59)$ & $2.85(1.42)$ \\
\hline After how many years would you celebrate your & 15 & $3.37(1.41)$ & $3.19(1.43)$ & $3.05(1.19)$ \\
\hline
\end{tabular}




\begin{tabular}{|c|c|c|c|c|}
\hline crystal anniversary? & & & & \\
\hline $\begin{array}{l}\text { How many steps would you have to take before } \\
\text { you reach the first level of the Eiffel Tower? }\end{array}$ & 300 & $3.30(1.47)$ & $3.55(1.65)$ & $3.55(1.57)$ \\
\hline $\begin{array}{l}\text { How many sheets of toilet paper are averagely } \\
\text { used up by a person per day? }\end{array}$ & 57 & $3.21(1.41)$ & $3.60(1.63)$ & $3.25(1.62)$ \\
\hline How many noses do slugs have? & 4 & $3.50(1.63)$ & $3.57(1.67)$ & $3.65(1.76)$ \\
\hline $\begin{array}{l}\text { Which British prime minister was awarded the } \\
\text { Nobel Price of Literature? }\end{array}$ & Churchill & $2.74(1.45)$ & $4.41(1.34)$ & $3.15(1.66)$ \\
\hline $\begin{array}{l}\text { On average how much time do women take to put } \\
\text { makeup on in their life time? }\end{array}$ & Over one year & $4.08(1.65)$ & $3.12(1.56)$ & $3.20(1.70)$ \\
\hline $\begin{array}{l}\text { How many lemons can a lemon tree produce } \\
\text { averagely? }\end{array}$ & 1500 & $3.26(1.45)$ & $3.67(1.50)$ & $4.25(1.71)$ \\
\hline How many tentacles does a squid have? & 10 & $2.98(1.46)$ & $3.84(1.25)$ & $3.55(1.10)$ \\
\hline What is the life span of a dragon fly? & 24 hours & $3.19(1.47)$ & $4.29(1.64)$ & $3.30(1.69)$ \\
\hline What type of creature is a dugite? & Snake & $3.32(1.46)$ & $3.90(1.59)$ & $3.40(1.57)$ \\
\hline $\begin{array}{l}\text { Who was the last English king to be killed in } \\
\text { battle? }\end{array}$ & Richard III & $3.07(1.46)$ & $4.40(1.32)$ & $2.85(1.46)$ \\
\hline When was the first 3D film released? & 1922 & $3.34(1.43)$ & $3.83(1.49)$ & $3.20(1.61)$ \\
\hline $\begin{array}{l}\text { By number of films made which country has the } \\
\text { largest film industry? }\end{array}$ & India & $3.21(1.51)$ & $4.17(1.32)$ & $2.95(1.61)$ \\
\hline $\begin{array}{l}\text { On average, how much time does a person spend } \\
\text { kissing in their lifetime? }\end{array}$ & 20,160 minutes & $4.15(1.51)$ & $3.35(1.63)$ & $3.40(1.54)$ \\
\hline What is the oldest university in Britain? & $\begin{array}{l}\text { Oxford } \\
\text { University }\end{array}$ & $3.65(1.62)$ & $4.06(1.83)$ & $3.00(1.69)$ \\
\hline $\begin{array}{l}\text { Where would you find the smallest bone in a } \\
\text { human body? }\end{array}$ & Ear & $3.31(1.49)$ & $4.15(1.51)$ & $3.85(1.76)$ \\
\hline What is the first country that used postcards? & Austria & $3.17(1.46)$ & $3.18(1.45)$ & $2.15(1.27)$ \\
\hline What are the smallest types of bird? & Hummingbird & $3.23(1.44)$ & $4.57(1.40)$ & $3.70(1.42)$ \\
\hline $\begin{array}{l}\text { What is the busiest single-runway airport in the } \\
\text { world? }\end{array}$ & London Gatwick & $3.30(1.44)$ & $4.19(1.40)$ & $3.00(1.72)$ \\
\hline $\begin{array}{l}\text { How many times per year on average does the } \\
\text { human eye blink? }\end{array}$ & 4,2 million & $3.97(1.49)$ & $3.80(1.67)$ & $2.80(1.77)$ \\
\hline Granadilla is another name for which fruit? & Passion fruit & $3.44(1.60)$ & $4.30(1.41)$ & $3.35(1.73)$ \\
\hline $\begin{array}{l}\text { What was referred to as the Second War for } \\
\text { Independence? }\end{array}$ & The war of 1812 & $3.35(1.64)$ & $4.48(1.39)$ & $3.60(1.54)$ \\
\hline $\begin{array}{l}\text { How many primary school pupils worldwide } \\
\text { dropped out of school in } 2012 ?\end{array}$ & 31 million & $3.97(1.53)$ & $3.94(1.67)$ & $3.25(1.55)$ \\
\hline $\begin{array}{l}\text { On average, how many times can a woodpecker } \\
\text { peck per second? }\end{array}$ & 20 & $3.53(1.50)$ & $4.25(1.46)$ & $3.45(1.70)$ \\
\hline $\begin{array}{l}\text { How much does the Queen of England cost the } \\
\text { public each year? }\end{array}$ & $£ 36.2$ million & $3.85(1.60)$ & $4.01(1.51)$ & $3.40(1.27)$ \\
\hline How long is the longest movie on earth? & 85 hours & $4.13(1.44)$ & $3.76(1.62)$ & $3.20(1.77)$ \\
\hline In which part of a shrimp's body can you find its & Head & $3.92(1.29)$ & $3.72(1.47)$ & $2.85(1.73)$ \\
\hline
\end{tabular}




\begin{tabular}{|c|c|c|c|c|}
\hline heart? & & & & \\
\hline What are the longest cells in the body? & Motor neurons & $3.56(1.47)$ & $4.29(1.54)$ & $2.90(1.62)$ \\
\hline $\begin{array}{l}\text { On average how many breaths does a human } \\
\text { take a day? }\end{array}$ & 5 million & $3.51(1.37)$ & $4.17(1.41)$ & $3.30(1.38)$ \\
\hline Where would you find the Sea of Tranquillity? & Moon & $3.59(1.43)$ & $4.60(1.22)$ & $3.30(1.63)$ \\
\hline What was the bloodiest war in U.S. history? & Civil War & $3.80(1.59)$ & $4.27(1.39)$ & $3.80(1.54)$ \\
\hline $\begin{array}{l}\text { In which year did Niagara Falls freeze up } \\
\text { completely? }\end{array}$ & 1932 & $3.76(1.49)$ & $4.20(1.51)$ & $3.60(1.82)$ \\
\hline $\begin{array}{l}\text { On average how many hours do we spend } \\
\text { eating? }\end{array}$ & 38,000 & $3.75(1.46)$ & $4.03(1.34)$ & $3.40(1.76)$ \\
\hline Which is the largest desert in the world? & Antarctica & $3.25(1.49)$ & $4.81(1.24)$ & $3.30(1.45)$ \\
\hline How does Ebola spread? & $\begin{array}{l}\text { Through body } \\
\text { fluids }\end{array}$ & $3.39(1.38)$ & $4.56(1.15)$ & $3.95(1.50)$ \\
\hline $\begin{array}{l}\text { In which country is it illegal to produce and } \\
\text { distribute adult movies? }\end{array}$ & North Korea & $3.85(1.55)$ & $4.08(1.32)$ & $3.40(1.70)$ \\
\hline Which is the hottest planet in the solar system? & Venus & $3.60(1.43)$ & $4.38(1.26)$ & $3.30(1.59)$ \\
\hline $\begin{array}{l}\text { To prevent damage, what did soldiers during } \\
\text { World War II use to cover their rifles? }\end{array}$ & Condoms & $3.79(1.36)$ & $4.27(1.48)$ & $3.45(1.57)$ \\
\hline How many banks are robbed averagely per day? & 20 & $4.49(1.34)$ & $3.62(1.42)$ & $3.40(1.54)$ \\
\hline $\begin{array}{l}\text { How many people on the planet use a mobile } \\
\text { phone? }\end{array}$ & 68 billion & $3.97(1.36)$ & $4.03(1.39)$ & $3.35(1.79)$ \\
\hline $\begin{array}{l}\text { What percentage of people in the world have } \\
\text { never made or received a phone call? }\end{array}$ & Over $50 \%$ & $4.29(1.52)$ & $3.99(1.48)$ & $3.65(1.35)$ \\
\hline $\begin{array}{l}\text { What colour would Coca Cola be if you were to } \\
\text { remove the artificial colouring? }\end{array}$ & Green & $4.73(1.32)$ & $3.87(1.77)$ & $3.70(1.69)$ \\
\hline $\begin{array}{l}\text { Which mammal holds the records of having the } \\
\text { quickest sexual intercourse? }\end{array}$ & Chimpanzee & $4.39(1.35)$ & $3.91(1.47)$ & $3.55(1.70)$ \\
\hline What is the fear of being buried alive known as? & Taphephobia & $3.76(1.47)$ & $4.60(1.31)$ & $3.50(1.67)$ \\
\hline $\begin{array}{l}\text { Which is the most abundant element in the } \\
\text { universe? }\end{array}$ & Hydrogen & $3.71(1.47)$ & $4.80(1.41)$ & $2.90(1.29)$ \\
\hline $\begin{array}{l}\text { What was the first planet to be discovered using a } \\
\text { telescope, in } 1781 ?\end{array}$ & Uranus & $3.75(1.40)$ & $4.68(1.30)$ & $3.20(1.54)$ \\
\hline In the human body what is the hallux? & Big toe & $3.80(1.48)$ & $4.81(1.33)$ & $4.20(1.32)$ \\
\hline Where is the windiest place on earth? & Port Martin & $3.50(1.38)$ & $4.90(1.44)$ & $2.75(1.59)$ \\
\hline $\begin{array}{l}\text { How many pounds of skin will you shed in a } \\
\text { lifetime? }\end{array}$ & 40 & 3.76 (1.39) & $4.63(1.31)$ & $3.40(1.79)$ \\
\hline $\begin{array}{l}\text { If you lived on the planet Mercury, how long would } \\
\text { a year last? }\end{array}$ & 88 days & $4.05(1.38)$ & $4.35(1.38)$ & $3.60(1.79)$ \\
\hline How long does sunlight take to reach earth? & $\begin{array}{l}8 \text { min and } 20 \\
\text { sec }\end{array}$ & $3.77(1.48)$ & $4.17(1.23)$ & $3.80(1.74)$ \\
\hline The human brain is $80 \%$ what? & Water & $3.80(1.69)$ & $4.73(1.10)$ & $2.95(1.57)$ \\
\hline How many eyes do bees have? & 5 & $3.70(1.21)$ & $4.60(1.23)$ & $3.65(1.50)$ \\
\hline What is the longest word with one vowel? & Strengths & $3.86(1.55)$ & $4.90(1.27)$ & $2.85(1.60)$ \\
\hline
\end{tabular}




\begin{tabular}{|c|c|c|c|c|}
\hline What was ketchup used to treat in the 1800 s? & Diarrhoea & $4.33(1.49)$ & $4.45(1.52)$ & $3.90(1.45)$ \\
\hline $\begin{array}{l}\text { An adult has } 206 \text { bones. How many does a child } \\
\text { have? }\end{array}$ & 300 & $3.59(1.34)$ & $4.86(1.08)$ & $3.15(1.69)$ \\
\hline $\begin{array}{l}\text { In the last } 3500 \text { years, how many years of } \\
\text { civilised peace have there been? }\end{array}$ & 230 & $4.04(1.80)$ & $5.10(1.32)$ & $3.20(1.70)$ \\
\hline What sauce was once sold as medicine ? & Ketchup & $4.25(1.21)$ & $4.37(1.53)$ & $3.20(1.51)$ \\
\hline What is the main symptom for the virus Ebola? & Vomiting & $3.78(1.22)$ & $4.73(1.36)$ & $3.25(1.74)$ \\
\hline What is the strongest bone in a human body? & $\begin{array}{l}\text { Femur } \\
\text { (thighbone) }\end{array}$ & $3.82(1.33)$ & $4.94(1.06)$ & $3.80(1.67)$ \\
\hline $\begin{array}{l}\text { Which colour can the human eye distinguish the } \\
\text { most shades of? }\end{array}$ & Green & $4.39(1.05)$ & $4.86(1.24)$ & $3.45(1.70)$ \\
\hline $\begin{array}{l}\text { A team of scientists found a way to turn peanut } \\
\text { butter into what? }\end{array}$ & Diamonds & $4.26(1.53)$ & $4.57(1.33)$ & $3.50(193)$ \\
\hline Which animal has the largest eye in the world? & Giant squid & $4.02(1.21)$ & $4.58(1.32)$ & $2.50(1.47)$ \\
\hline Which animal has a brain smaller than its eye? & Ostrich & $4.33(1.48)$ & $4.42(1.23)$ & $3.05(1.61)$ \\
\hline What proportion of Earth's size is the moon? & $27 \%$ & $3.89(1.34)$ & $4.98(1.21)$ & $3.35(1.35)$ \\
\hline What is the most dangerous chemical? & Digoxin & $4.12(1.40)$ & $4.69(1.26)$ & $3.20(1.82)$ \\
\hline $\begin{array}{l}\text { If you had pogonophobia what would you be } \\
\text { afraid of? }\end{array}$ & Beards & $4.28(1.19)$ & $4.40(1.36)$ & $2.80(1.51)$ \\
\hline How many inches do astronauts grow in space? & 2 & $4.26(1.50)$ & $4.62(1.27)$ & $4.00(1.41)$ \\
\hline $\begin{array}{l}\text { What fruit is efficient in waking you up in the } \\
\text { morning? }\end{array}$ & Apple & $4.45(1.51)$ & $4.55(1.23)$ & $3.80(1.74)$ \\
\hline On average how long do we sleep in our life time? & 26 years & $4.28(1.30)$ & $4.70(1.36)$ & $3.75(1.65)$ \\
\hline Where is the hottest place on earth? & Dallol & $4.06(1.35)$ & $4.81(1.06)$ & $3.20(1.47)$ \\
\hline How many muscles do you use when you speak? & 75 & $4.09(1.23)$ & $4.88(1.17)$ & $3.70(1.53)$ \\
\hline $\begin{array}{l}\text { On average how many words a day does a } \\
\text { person speak? }\end{array}$ & 4,800 & $4.34(1.18)$ & $4.74(1.36)$ & $3.75(1.48)$ \\
\hline $\begin{array}{l}\text { If a human eats a polar bear's liver, what would } \\
\text { happen? }\end{array}$ & Death & $4.87(1.35)$ & $4.56(1.54)$ & $3.60(1.47)$ \\
\hline $\begin{array}{l}\text { On average how many dreams does a person } \\
\text { have a night? }\end{array}$ & 7 & $4.82(1.27)$ & $4.63(1.50)$ & $3.60(1.76)$ \\
\hline Which body parts never stop growing? & Ears and nose & $4.22(1.21)$ & $4.92(1.29)$ & $3.70(1.53)$ \\
\hline What is four times hotter than the sun? & A lightning bolt & $4.39(1.32)$ & $4.90(1.22)$ & $3.85(1.69)$ \\
\hline What is lighter as a solid than a liquid? & Water & $4.66(1.23)$ & $4.88(1.45)$ & $3.20(1.58)$ \\
\hline $\begin{array}{l}\text { Falling in love has a similar neurological effect to } \\
\text { what drug? }\end{array}$ & Cocaine & $5.02(1.04)$ & $4.65(1.41)$ & $3.70(1.69)$ \\
\hline Which animal doesn't grow old and die? & Lobster & $4.79(1.27)$ & $5.16(1.21)$ & $3.45(1.67)$ \\
\hline Which body part stays the same size since birth? & Eyes & $4.66(1.21)$ & $5.05(0.90)$ & $3.40(1.70)$ \\
\hline
\end{tabular}

